\title{
ОСОБЕННОСТИ ФЕРРОКИНЕТИКИ И ПАРАМЕТРОВ СИСТЕМНОГО ВОСПАЛЕНИЯ У ПАЦИЕНТОВ С САХАРНЫМ ДИАБЕТОМ
}

\author{
Мусина Н.Н., Саприна Т.В., Прохоренко Т.С., Зима А.П.
}

ФГБОУ ВО «Сибирский государственный медицинский университет» Минздрава России, г. Томск, Россия

ЦЕЛЬ: изучить клинико-биохимические корреляции параметров феррокинетики, системного воспаления и метаболического контроля у пациентов с сахарным диабетом.

МАТЕРИАЛЫ И МЕТОДЫ: исследование проводилось на базе эндокринологической клиники ФГБОУ ВО СибГМУ г. Томска. В исследование было включено 20 пациентов с сахарным диабетом 1 и 56 пациентов с сахарным диабетом 2 типа. Всем пациентам проводились: исследование гликированного гемоглобина; исследование уровня креатинина с расчетом скорости клубочковой фильтрации по формуле CKD-EPI, оценивались количество эритроцитов, ретикулоцитов, концентрация гемоглобина, уровень гематокрита и биохимические показатели обмена железа - концентрация сывороточного железа и ферритина; проводилась оценка концентрации гепсидина и маркеров воспаления - СОЭ и высокочувствительного С-реактивного белка (СРБ). Корреляцию между признаками оценивали с помощью критерия Спирмена, пороговый уровень значимости был принят равным 0,05.

PЕЗУЛЬтАТЫ: парный корреляционный анализ в группе пациентов с сахарным диабетом 2 типа выявил наличие положительной корреляцией СОЭ с микроальбуминурией $(r=0,412 ; p=0,002)$ и содержанием креатинина $(r=0,458 ; p=0,001)$, отрицательной - c СКФ $(r=-0,368 ; p=0,006)$, содержанием железа сыворотки ( $r=-0,283 ; p=0,038)$, количеством эритроцитов $(r=-0,639 ; p<0,0001)$, уровнем гемоглобина $(r=-0,453$; $\mathrm{p}=0,001)$ и гематокрита $(r=-0,472 ; p=0,001)$; данные корреляционные связи отражают роль нарушения функции почек в развитии системного воспаления и анемии. В группе пациентов с сахарным диабетом 2 типа концентрация ферритина положительно коррелировала с активностью трансаминаз крови - АCT $(r=0,505 ; p<0,0001)$ и AЛТ $(r=0,442 ; p=0,002)$. Уровень железа сыворотки положительно коррелировал с активностью как ACT ( $r=0,560 ; p<0,0001)$, так и AЛТ $(r=0,559 ; p<0,0001)$, что подтверждает роль нарушения функции печени в развитии системного воспаления и синдрома дисметаболической перегрузки железом.

В группе пациентов с сахарным диабетом 1 типа микроальбуминурия положительно коррелировала c COЭ $(r=0,697 ; p=0,001)$ и количеством лейкоцитов ( $r=0,615 ; p=0,005)$ и отрицательно с количеством эритроцитов ( $r=-0,510 ; p=0,026)$. СОЭ положительно коррелировала с концентрацией креатинина $(r=0,501$; $\mathrm{p}=0,024)$, отрицательно - со скоростью клубочковой фильтрации $(r=-0,553 ; p=0,012)$. Были выявлены корреляционные связи СОЭ с параметрами феррокинетики: положительная связь с количеством ретикулоцитов крови ( $r=0,632 ; p=0,05)$, отрицательная корреляционная связь с количеством эритроцитов $(r=-0,768 ; p<0,0001)$, гемоглобина $(r=-0,527 ; p=0,017)$ и гематокритом $(r=-0,556 ; p=0,021)$.

Выводы: установленные корреляционные связи отражают взаимоотягощающее влияние системного воспаления и нарушений углеводного обмена, а также отражают роль системного воспаления в развитии анемического синдрома. Полученные положительные корреляционные связи активности трансаминаз с параметрами метаболизма железа подтверждают роль нарушений функции печени в развитии и прогрессировании нарушений феррокинетики у пациентов с ожирением и дисгликемией.

ИСТОЧНИК ФИНАНСИРОВАНИЯ. Исследование выполнено при финансовой поддержке гранта РФФИ Аспиранты №19-315-90061 «Взаимосвязь нарушений феррокинетики и метаболических изменений при сахарном диабете». 